\title{
The effects of horseback riding participation on the muscle tone and range of motion for children with spastic cerebral palsy
}

\author{
Kwang Baik', Jung-Kyun Byeun ${ }^{2 * *}$, Jae-Keun Baek ${ }^{3}$ \\ 'Department of Rehabilitation Personal Training, College of Rehabilitation Welfare Education, Konyang University, NonSan, Korea \\ ${ }^{2}$ Department of Adapted Physical Education, Korea National Sport University, Seoul, Korea \\ ${ }^{3}$ Department of Adapted Physical Education, College of Sport Science, Soonchunhyang University, Asan, Korea
}

The objective of this research is to verify the effects of horseback riding participation on the muscle tone of pelvic limbs and articular range of motion for children with spastic cerebral palsy. The research target is 16 children with spastic cerebral palsy, 8 children for the experimental group and 8 children for the control group. As a tool to measure the muscle tone, Modified Ashworth Scale (MAS), was used and a goniometer was used to measure the range of motion (ROM). A therapeutic horseback riding program was conducted to an experimental group of 8 children with spastic cerebral palsy in the therapeutic horseback riding for 60 min a day, 2 days a week and a total of 12 weeks. The results are as follows: First, the participation in the therapeutic horseback riding program showed a statistically significant difference in the muscle tone for the knee of children with spastic cerebral palsy $(P<0.01)$. Sec-

\section{INTRODUCTION}

The common characteristics observed in children with cerebral palsy are spasticity, weakened muscle, change of muscular skeletal system, and decrease of pelvic movement (Quint and Toomey, 1998; van der Heide et al., 2005; Wollacott et al., 1998), and one of the most important problems is the lack of posture control (van der Heide et al., 2005).

Hippotherapy is a method of treatment to improve the function of neural muscles, and due to the movement of living horses, horseback riders experience 500 to 1,000 bodily movements in $10 \mathrm{~min}$. In addition, the movement generated by the walk of horses has the riders experience 3-dimensional motion (forward/backward, ond, though the difference in knee muscle tone between the experimental group and the control group was statistically insignificant, the average was improved by the participation. Third, the participation in the therapeutic horseback riding program showed a statistically significant difference in the hip-joint motion range for the knee of children with spastic cerebral palsy $(P<0.01)$. Fourth, though the difference in the hip joint motion range between the experimental group and the control group was statistically insignificant, the average was improved by the participation.

Keywords: Horseback riding, Muscle tone, Range of motion, Spastic cerebral palsy
${ }^{*}$ Corresponding author: Jung-Kyun Byeun

Department of Adapted Physical Education, Korea National Sport University,

1239 Yangjae-daero, Songpa-gu, Seoul 138-763, Korea

Tel: +82-2-410-6938, Fax: +82-2-410-6765, E-mail: bluebjk@gmail.com

Received: May 31, 2014 / Accepted: September 30, 2014 left/right, upward/downward). It was reported that the movement of horses transmitted to the riders is similar to the pattern of movement which occurs in the pelvis of walking humans and generates the same feeling of motion effects as the riders themselves walk (Debuse et al., 2005; Herrero et al., 2010). The rhythmic and repeated movement of horses through horseback riding provides the riders with sensory input, which stimulates superior motor nerve along upward neurotabes (Debuse et al., 2005; Herrero et al., 2010), and activates the neural circuit of voluntary movement (Han et al., 2004).

On the basis of such mechanism, it was reported that therapeutic horseback riding not only provides such physical effects as muscular strength, agility improvement, sense of balance, posture 
improvement, body support capability, eye-hand coordination, and improvement of blood circulation but also brings in internal/ external confidence while controlling a horse, and that it also provides such various cognitive learning effects as order of tasks, left/ right distinction, sensory integration, space sense, and exercise planning (Benda et al., 2003).

Especially, therapeutic horseback riding was effective in reducing the spasticity of patients with spinal cord injury and the more spastic the patients, the more effective the therapeutic riding (Lechner et al., 2003). In addition, it was reported that it reduces the spasticity of elbow joint bending and knee joint bending for children with spastic cerebral palsy (Lee et al., 2011) and is effective in increasing the articular motion range of pelvic limbs (Shurtleff et al., 2009).

Children with cerebral palsy use extensor muscles excessively in order to maintain their sitting posture, mobilize muscles abnormally, and use antagonistic muscles excessively (Brogren et al., 1998; Liao et al., 2003). The proper posture during horseback riding is to maintain $90^{\circ}$ hip joint and $90^{\circ}$ knee joint, and such posture induces decrease in the muscle tone and spasticity of the riders. The posture of children during horseback riding naturally alleviates the tension and enables functional movement. While taking therapeutic riding, children with cerebral palsy recovers an appropriate posture, and maintaining the appropriate posture plays an important role of reducing the spasticity (Meregillano, 2004).

Thus, this research aims at verifying the effects of therapeutic horseback riding on the muscle tone of pelvic limbs and range of articular motion for children with spastic cerebral palsy.

\section{MATERIALS AND METHODS}

\section{Research target}

The target of this research consists of a total of 16 children, 8 children for the experimental group and 8 children for the control group. The experimental group is children with cerebral palsy who take part in the therapeutic horseback riding program at $\mathrm{H}$ therapeutic riding track of $\mathrm{H}$ company and the control group is children with cerebral palsy who reside in $S$ rehabilitation center of $\mathrm{S}$ city. The handicapped classification of cerebral palsy is diverse, but the spastic cerebral palsy was selected in this research.

Table 1. General characteristics of research target

\begin{tabular}{lcrc}
\hline Group & \multicolumn{1}{c}{ Age } & Height $(\mathrm{cm})$ & Weight $(\mathrm{kg})$ \\
\hline Experimental group $(\mathrm{n}=8)$ & $12.12 \pm 3.60$ & $135.0 \pm 21.92$ & $33.12 \pm 13.76$ \\
Control group $(\mathrm{n}=8)$ & $8.12 \pm 2.58$ & $133.12 \pm 11.74$ & $32.75 \pm 12.00$ \\
\hline
\end{tabular}

The general characteristics of this research target are given in the following Table 1 .

\section{Measurement tool and method}

In this research, Modified Ashworth Scale (MAS) was used to measure the muscle tone, and a passive goniometer was used to measure the range of motion (ROM) of the hip joint. The sick knee was selected as the measuring part for the muscle tone and hip joint ROM of children with cerebral palsy.

\section{1) Modified Ashworth Scale (MAS)}

The 6 grades of the modified Ashworth scale are given in the following Table 2 .

\section{2) Goniometer}

In this research, in order to measure the hip joint ROM of children with cerebral palsy, used was a passive goniometer.

\section{3) Measurement method}

In this research, the measurement was conducted at $\mathrm{H}$ Therapeutic Horseback Riding Track of $\mathrm{H}$ company and S Rehabilitation Center of $S$ city. In order to minimize the error of measured values, the measurement was made by $\mathrm{Mr}$. $\mathrm{P}$, an occupational therapist with $5+$ years of experience, and Mr. B and Mr. K. majors in special physical education. The measurement was made twice, and the higher value was selected. In order to maximize the psychological stability of children with cerebral palsy, if necessary, the children were accompanied by their parents, and the measurement was made on the bed.

\section{Therapeutic horseback riding program}

A therapeutic horseback riding program was conducted to an experimental group of 8 children with spastic cerebral palsy in the

Table 2. Modified Ashworth Scale of muscle spasticity

Modified Ashworth Scale of muscle spasticity
G0 No increase in muscle tone
G1 In case the sick side is moved by bending or stretching, at the end of the
articular motion range, a little resistance is detected and the muscle
tone increases a little.


Therapeutic Horseback Riding 60 min a day, 2 days a week and a total of 12 weeks and the daily program consisted of $10 \mathrm{~min}$ of warm-up, 40 min of workout, and $10 \mathrm{~min}$ of cool-down.

\section{Data processing}

The data of this research were analyzed in accordance with the research objective by using SPSS 20.0 for-Windows Program. The characteristics of children with spastic cerebral palsy were compared by calculating the average $(M)$ and the standard deviation $(S D)$. The ex ante and ex post changes for the muscle tone of limbs within a group were compared by using the t-test of two dependent (responsive) samples (two-dependent samples t-test; matched pair t-test), and the ex post change between groups by using the t-test of two independent samples (two-independent samples $t$ -test). The statistical level of significance was set to $P<0.05$.

\section{Results}

\section{Results for knee muscle tone within experimental group}

In order to understand the effects of the therapeutic horseback riding program, the ex ante and ex post knee muscle tones were compared by using the t-test of two dependent samples, and the results are given in the following Table 4.

The statistical significance for the difference between the ex ante knee-joint muscle tone and the ex post knee-joint muscle tone was verified, and the results indicate that the t-statistical value is -3.742 and the significance probability is 0.007 , showing that in the significance level of 0.01 , this difference is similar to the difference between the ex ante and ex post knee muscle tones of children with spastic cerebral palsy, measured in an aqua rehabilitation exercise program.

Table 3. Therapeutic horseback riding program

\begin{tabular}{|c|c|c|}
\hline Classification & Therapeutic horseback riding program & Time (min \\
\hline Warm-up & $\begin{array}{l}\text { - Warm-up gymnastics and stretching together with } \\
\text { the leader and side workers }\end{array}$ & 10 \\
\hline Workout & $\begin{array}{l}\text { - Move by walking (Left direction, Right direction) } \\
\text { - Play balls while walking (Play balls with one hand } \\
\text { and two hands, Shoot basketballs into goals) } \\
\text { * Ride horses together, depending on the degree of } \\
\text { disorder for children with cerebral palsy. } \\
\text { * Contact lumbar, pelvis, knee, and ankle. } \\
\text { * If necessary, use an elastic band instead of a general } \\
\text { stirrup }\end{array}$ & 40 \\
\hline Cool-down & $\begin{array}{l}\text { Cool-down gymnastics and stretching together with } \\
\text { the leader and side workers. }\end{array}$ & 10 \\
\hline
\end{tabular}

\section{Results for knee muscle tone within control group}

In order to understand the effects of the therapeutic horseback riding program, the ex ante and ex post knee muscle tones were compared by using the t-test of two dependent samples, and the results are given in the following Table 5 .

The statistical significance for the difference between the ex ante knee-joint muscle tone and the ex post knee-joint muscle tone was verified, and the results indicate that the t-statistical value is -1.00 and the significance probability is 0.351 , showing that in the significance level of 0.01 , this difference is insignificant in comparison with the difference between the ex ante and ex post knee muscle tones of children with spastic cerebral palsy, measured in an aqua rehabilitation exercise program.

\section{Results for difference in knee-joint muscle tone between experimental and control group}

In order to understand the difference in the knee-joint muscle tone of children with spastic cerebral palsy, the t-test of two independent samples was performed. And the results are given in $\mathrm{Ta}-$ ble 6 .

The t-statistical value for the difference in the knee-joint muscle tone between the experimental group and the control group is 1.497 and the significance probability is 0.168 , showing that in the significance level of 0.05 , there is no analytical difference in the knee-joint muscle tone between the two groups.

\section{Results for hip joint ROM within experimental group}

In order to understand the effects of the therapeutic horseback riding program, the ex ante and ex post knee joint range of motion were compared by using the t-test of two dependent samples, and the results are given in Table 7 .

The statistical significance for the difference between the ex ante

Table 4. Results for knee-joint muscle tone of experimental group (Unit: stage)

\begin{tabular}{lcccc}
\hline Muscle tone & Before & After & $t$ & $P$ \\
\hline Knee joint & $3.75 \pm 1.03$ & $4.75 \pm 0.70$ & -3.742 & 0.007 \\
\hline${ }^{* *} P<0.01$ & & & &
\end{tabular}

Table 5. Results for knee-joint muscle tone of control group

(Unit: stage)

\begin{tabular}{lcccc}
\hline Muscle tone & Before & After & $\mathrm{t}$ & $P$ \\
\hline Knee joint & $3.62 \pm 1.59$ & $3.75 \pm 1.75$ & -1.00 & 0.351 \\
\hline
\end{tabular}

Table 6. Results for knee-joint muscle tone

(Unit: stage)

\begin{tabular}{lcccc}
\hline Muscle tone & Experimental & Control & $\mathrm{t}$ & $P$ \\
\hline Knee joint & $4.75 \pm 0.70$ & $3.75 \pm 1.75$ & 1.497 & 0.168 \\
\hline
\end{tabular}


Table 7. Results for knee joint range of motion

\begin{tabular}{lcccc}
\hline ROM & Before & After & $t$ & $P$ \\
\hline Hip joint & $21.87 \pm 3.72$ & $25.62 \pm 4.95$ & -4.583 & 0.003 \\
\hline${ }^{* *} P<0.01$ & & & &
\end{tabular}

Table 8. Results for knee joint range of motion

\begin{tabular}{lcccc}
\hline ROM & Before & After & $\mathrm{t}$ & $P$ \\
\hline Hip joint & $23.12 \pm 3.72$ & $23.75 \pm 4.43$ & -0.552 & 0.598 \\
\hline
\end{tabular}

Table 9. Results for knee joint ROM

\begin{tabular}{lcccc}
\hline ROM & Experimental & Control & $\mathrm{t}$ & $P$ \\
\hline Hip joint & $25.62 \pm 4.95$ & $23.75 \pm 4.43$ & 0.798 & 0.438 \\
\hline
\end{tabular}

hip joint range of motion and the ex post hip joint range of motion was verified, and the results indicate that the $t$ statistical value is -4.583 , and the significance probability is 0.003 , showing that in the significance level of 0.01 , the therapeutic horseback riding program provides an analytical difference between the ex ante and ex post hip joint range of motion of children with cerebral palsy.

\section{Results for hip joint ROM within control group}

In order to understand the effects of the therapeutic horseback riding program, the ex ante and ex post knee joint range of motion were compared by using the t-test of two dependent samples, and the results are given in Table 8 .

The statistical significance for the difference between the ex ante hip joint range of motion and the ex post hip joint range of motion was verified, and the results indicate that the $t$ statistical value is -0.0552 , and the significance probability is 0.598 , showing that in the significance level of 0.01 , the therapeutic horseback riding program provides no analytical difference between the ex ante and ex post hip joint range of motion of children with cerebral palsy.

\section{Results for difference in hip joint ROM between experimental and control group}

In order to understand the difference in the hip joint range of motion of children with spastic cerebral palsy, the t-test of two independent samples was performed. and the results are given in Table 9.

The t-statistical value for the difference in the hip joint range of motion between the experimental group and the control group is 0.798 , and the significance probability is 0.438 , showing that in the significance level of 0.05 , there is no analytical difference in the hip joint range of motion between the two groups.

\section{DISCUSSION}

This research aimed at verifying the effects of therapeutic horseback riding on children with spastic cerebral palsy by comparing the muscle tone of pelvic limbs and articular range of motion within the experimental/control groups and between the experimental and control groups. No statistically significant difference in the knee muscle tone and hip joint range of motion between the experimental group and control group of children with spastic cerebral palsy was observed, but since the average was improved, therapeutic horseback riding is considered to have a positive effect on the knee muscle tone and hip joint range of motion of children with spastic cerebral palsy.

The major aim of horseback riding activities for people with cerebral palsy is to optimize the arrangement and symmetry of the body itself. This is accomplished by an appropriate posture on horses which minimizes or relaxes muscle tone, inducing a normal reaction to an abnormal stimulation (Meregillano, 2004). Moreover, regarding the effective exercise type of people with cerebral palsy, Huberman (1976) emphasized the activities to develop muscular strength, endurance, flexibility and balance, and the stretching of flexor muscle and strengthening of extensor muscle to alleviate the spasticity, rather than the activities requiring an excessive stimulation, tension, and fatigue. In this point of view, the results of this research comply with the major target of the therapeutic horseback riding, which is considered to be an appropriate and effective exercise type to children with cerebral palsy.

Riding on horses requires contraction and relaxation of all the muscles inside the thigh. In case of riding on horses without stirrups, the gravity helps relax calf muscles. In case of riding on horses with stirrups on, the gravity helps relax heel tendon. Such balancing exercise of muscles reduces one-leg movement and the balanced use of two legs prevents riding posture from leaning to one direction. To make such a right posture and remember such a right bodily movement is considered to be an effect of horseback riding (Jung et al., 2011).

Lee et al. (2011) applied an 8-week therapeutic horseback riding program to 9 children with spastic diplegia, and the results indicate that the spasticity of elbow joint bending and knee joint bending decreased significantly. In this research, the average of the knee muscle tone for children with spastic cerebral palsy within the experimental group was found to decrease with a statistical significance and support prior research $(P<0.01)$, but the difference in the knee muscle tone between the experimental and control groups was found to be statistically insignificant even though 
the average was improved $(P<0.05)$.

Kulkarni-Lambore et al. (2001) reported that the horseback riding provided to children with cerebral palsy improved significantly the right-side hip joint and the articular range of motion of knee and ankle, and the pelvic movement during the walk was close to normal, and Shurtleff et al. (2009) also reported that the horseback riding provided to children with spastic cerebral palsy increased the articular range of motion. Also in this research, the average of the hip joint range of motion for children with spastic cerebral palsy within the experimental group was improved, indicating an increase in the range of motion with a statistical significance and supporting prior research $(P<0.01)$, but the difference in the hip joint range of motion between the experimental and control groups was statistically insignificant even though the average was improved $(P<0.05)$.

In this research, the results for the knee muscle tone and hip joint range of motion of the experimental and control groups showed no significant difference between the two groups. It is considered that since the disorder characteristics of cerebral palsy give a different effect to each individual depending on the degree of disability, the effect of therapeutic horseback riding was cancelled out between the experimental and control groups. In addition, the treatment characteristics of children with cerebral palsy prevented a complete control to block the external treatment and activity of the experimental and control groups, and the same therapeutic riding program was applied even though the difference among individuals existed depending on the degree of disability. These view points are also considered to have acted as limitations. Clearly, however, the therapeutic horseback riding provided a positive effect to the knee muscle tone and hip joint range of motion of children with spastic cerebral palsy.

Exercise disorder is a result of damage and inappropriate change. It appears clearly as children grow and develop, and it gets serious as time passes (Hanna et al., 2009). Therefore, the exercise development of children with cerebral palsy should be expedited by implementing together with neoro-development treatment such diverse treatment approaches as therapeutic horseback riding, aqua-exercise therapy, sensory integrative therapy, music therapy, and psychotherapy (Catanese et al., 1995; Fetters and Kluzik, 1996; Reddihough et al., 1998). Moreover, since horseback riding itself is interesting to children with cerebral palsy (Sterba et al., 2002), it is expected to provide a synergistic effect to functional improvement of the children through the motivation which reduces the resistance to treatment and encourages an enthusiastic participation in therapeutic riding.
As the treatment of children with cerebral palsy focuses on the expedition and independence of mobility and functionality, it requires diverse approaches which include the degree of disability, neurological classification, exercise capacity, and psychological conditions (Steultjens et al., 2003). Therapeutic horseback riding also takes the same focuses and approaches as mentioned above. The common practice of therapeutic horseback riding, which may be accomplished by cooperation between leaders of therapeutic riding and therapists (physical therapist, work therapist, speech therapist, etc.), is expected to provide a great effect to children with cerebral palsy.

This research aimed at verifying the effects of therapeutic horseback riding on children with spastic cerebral palsy by applying a 12-week therapeutic horseback riding program (60 min a day, 2 days a week) to an experimental group composed of 8 children with spastic cerebral palsy and then comparing the muscle tone of pelvic limbs and articular range of motion. The conclusions made in this research are as follows: First, the participation in the therapeutic riding program showed a statistically significant difference in the knee muscle tone of children with spastic cerebral palsy $(P<0.01)$. Second, no statistically significant difference in the knee muscle tone between the experimental group, who participated in the therapeutic riding program, and the control group, who did not take part in the program, was observed, but the average was improved. Third, the hip joint range of motion of children with spastic cerebral palsy who took part in the therapeutic riding program showed a statistically significant difference $(P<0.01)$. Fourth, no statistically significant difference in the hip joint range of motion between the experimental group, who participated in the therapeutic riding program, and the control group, who did not take part in the program, was observed, but the average was improved.

This research implies that the effects of therapeutic horseback riding on children with spastic cerebral palsy are positive. Thus, it may be said that therapeutic riding is a rehabilitation exercise required for children with spastic cerebral palsy. In addition to the pelvic limbs research, a simultaneous investigation on the muscular activity of upper limbs and pelvic limbs would be a significant piece of research in the future. It is necessary to study a method to sustain the effect of spasticity reduction after therapeutic horseback riding. It will be also necessary to study a variety of techniques for application of therapeutic horseback riding to various types of cerebral palsy. 


\section{CONFLICT OF INTEREST}

No potential conflict of interest relevant to this article was reported.

\section{REFERENCES}

Benda W, McGibbon NH, Grant KL. Improvement in muscle symmetry in children with cerebral palsy after equine-assisted therapy (hippotherapy). J Altern Complement Med 2003;9:817-825.

Brogren E, Hadders-Algra M, Forssberg H. Postural control in sitting children with cerebral palsy. Neurosci Biobehav Rev 1998;22:591-596.

Catanese AA, Coleman GJ, King J, Reddihough DS. Evaluation of an early childhood programme based on principles of conductive: the Yooralla project. J Paediatr Child Health 1995;31:418-422.

Debuse D, Chandler C, Gibb C. An exploration of german and british physiotherapists' views on the effects of hippotherapy and their measurement. Physiother Theory Pract 2005;21:219-242.

Fetters L, Kluzik J. The effects of neurodevelopmental treatment versus practice on the reaching of children with cerebral palsy. Phys Ther 1996;76:346-358.

Han S, Choo H, Lee S. The effects of horseback riding on balance improvement of children with cerebral Palsy. The Korean J Phys Ed 2004;43:601-610.

Hanna SE, Rosenbaum PL, Bartlett DJ, Palisano RJ, Walter SD, Avery L, Russell DJ. Stability and decline in gross motor function among children and youth with cerebral palsy aged 2 to 21 years. Dev Med Child Neurol 2009;51:295-302.

Herrero P, Asensio Á, García E, Marco Á, Oliván B, Ibarz A, Gómez-Trullén EM, Roberto C. Study of the therapeutic effects of an advanced hippotherapy simulatorin children with cerebral palsy: a randomized controlled trial. BMC Muculoskelet Disord 2010;11:71.

Huberman G. Organized sport activities with cerebral palsied adolescents. Rehabil Lit 1976;37:103-107.

Jung S, Jung T, Cho H. The effects of horseback riding on equiibrium and spinal posture of children with cerebral palsy. J Adapted Phys Ed and Exercise 2011;19:79-90.
Kulkarni-Lambore S, McGuigan A, Narula N, Sepalak K. Kinematic gait analysis of an individual with cerebral palsy before and after hippotherapy. Phys Ther 2001;81:A40.

Lechner HE, Feldhaus S, Gudmundsen L, Hegemann D, Michel D, Zach GA, Knecht $H$. The short-term effect of hippotherapy on spasticity in patients with spinal cord injury. Spinal Cord 2003;41:502-505.

Lee I, Kim J, Lee S. The effects of hippotherapy on spasticity and muscular activity of children with cerebral palsy. J Korean Soc Occup Ther 2011;19:117-124.

Liao SF, Yang TF, Hsu TC, Chan RC, Wei TS. Differences in seated postural control in children with spastic cerebral palsy and children who are typically developing. Am J Phys Med Rehabil 2003;82:622-626.

Meregillano G. Hippotherapy. Phys Med Rehabil Clin N Am 2004;15:843854.

Quint C, Toomey M. Powered saddle and pelvic mobility: An investigation into the effects on pelvic mobility of children with cerebral palsy of a powered saddle which imitates the movements of a walking horse. Physiotherapy 1998;84:376-384.

Reddihough D, King J, Coleman G, Gatanese T. Efficacy of programmes based on conductive education for young children with cerebral palsy. Dev Med Child Neurol 1998;40:763-770.

Shurtleff TL, Standeven JW, Engsberg JR. Changes in dynamic trunk/ head control stability and functional reach after hippotherapy. Arch Phys Med Rehabil 2009;90:1185-1195.

Sterba J, Rogers B, France A, Vokes D. Horseback riding in children with cerebral palsy: Effect on gross motor function. Dev Med Child Neurol 2002;44:301-308.

Steultjens EEMJ, Dekker JJ, Bouter LM, Lambregts BB, Ende ECHM van den, Nes J van de. Occupational therapy for children with cerebral palsy: a systematic review. Clin Rehabil 2003;18:1-14.

Van der Heide JC, Fock JM, Otten B, Stremmelaar E, Hadders-Algra M. Kinematic characteristics of postural control during reaching inpreterm children with cerebral palsy. Pediatric Res 2005;58:586-593.

Wollacott MH, Burtner P, Jensen J, Jasiewica J, Roncesvalles N, Sveistrup $\mathrm{H}$. Development of postural responses during standing in healthy children and in children with spastic diplegia. Neurosci Biobehav Rev 1998;22:583-589. 